\title{
Precocious Puberty as a Result of Congenital Hypothyroidism
}

\author{
Petrit Hoxha ${ }^{1}$, Entela Puca ${ }^{2}$, Blertina Olldashi ${ }^{3}$, Agron Yllii ${ }^{4}$, Edmond Puca ${ }^{5 *}$ \\ ${ }^{1}$ Department of Pediatric Endocrinology, UHC “Mother Teresa” Tirana, Albania \\ ${ }^{2}$ Service of Endocrinology, Amerikan Hospital, Tirana, Albania \\ ${ }^{3}$ Service of Endocrinology, Hygeia Hospital, Tirana, Albania \\ ${ }^{4}$ Service of Endocrinology, UHC "Mother Teresa" Tirana, Albania \\ ${ }^{5}$ Service of Infectious Diseases, UHC "Mother Teresa" Tirana, Albania
}

*Corresponding author: Edmond Puca, Service of Infectious Diseases, UHC “Mother Teresa” Tirana, Albania.

To Cite This Article: Edmond Puca, Precocious Puberty as a Result of Congenital Hypothyroidism. Am J Biomed Sci \& Res. 2020 - 7(1). AJBSR. MS.ID.001114. DOI: 10.34297/AJBSR.2020.07.001114.

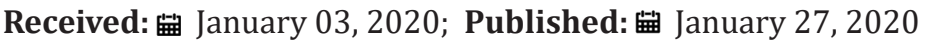

\begin{abstract}
Precocious puberty accepted when secondary sexual characteristics developed before the age of 8 in girls and 9 in boys. One of its causes is severe hypothyroidism. Severe hypothyroidism may rarely result in precocious puberty and the pathophysiology of it is uncertain yet. Fortunately, the puberty is reversible with the thyroid hormone administration. The aim of this presentation is to report an interesting case of precocious puberty and hypothyroidism, which is benign and easily treatable.
\end{abstract}

Keywords: Hypothyroidism, Precocious puberty, Ovarian cyst

\section{Introduction}

Precocious Puberty (PP) is widely accepted when secondary sexual characteristics developed before the age of 8 in girls and before the age of 9 in boys [1,2]. Severe hypothyroidism is a rare cause of precocious puberty. Congenital hypothyroidism, which is one of the causes of PP, occurs in approximately 1:2,000 to $1: 4,000$ newborns $[3,4]$. With the advent of screening of newborn populations, the incidence varies by geographic location, national screening programs, experience and other factors. Precocious puberty is present more commonly in girls than boys [5]. The most common manifestation are the slowing of growth velocity, lethargy, altered school performance, sluggishness, dry skin, constipation, facial puffiness, mild obesity, and less pseudo tumor cerebry and abdominal manifestations such as: acute abdominal distension, intestinal obstruction and gastrointestinal hypomotility etc. [6].

Thyroid hormone is essential for normal growth and neurologic development, particularly in the first few years of life, and hypothyroidism during this period is a leading cause of PP $[3,7]$. Premature puberty in girls is usually benign. In these rare cases, hypothyroidism leads to growth delay with, paradoxically, precocious puberty. We report a case of a 4.7-year-old girl diagnosed with congenital hypothyroidism who presented with vaginal bleeding, precocious puberty, and a large cyst on the right ovary. Our purpose is to emphasize the importance of hypothyroidism, which is benign and easily treatable, in the differential diagnosis of precocious puberty.

\section{Case Report}

A 4.7-year-old girl was referred by Obstetrics-Gynecology Service for endocrinological consultation. She presented with abdominal/pelvic pain and vaginal bleeding for one week and the child was using 3-4 pads a day. The child was diagnosed as a case with a right ovarian mass and was planned for surgery. She was born at term pregnancy without complication. The parents described the child as having a delay in development from infancy, but a formal developmental assessment had not been done until now. They said she had been quiet and inactive child. There was no family history of thyroid disease or precocious puberty. On objective examination she looked lethargic, pale and puffy face. 
Temperature was 36.6oC. Growth velocity was decreased and contrasted with exaggerated weight gain. She weighed $21 \mathrm{~kg}$ (weight 90th percentile), height was $92 \mathrm{~cm}$ (height $<3 \mathrm{rd}$ percentile), stature development was 2 year and 9 months, bone age corresponding to one year. Blood pressure was 95/60 $\mathrm{mmHg}$, heart rate 68 beats/ minute. Her pubertal development according to Tanner staging system was accelerated AOPOS2; breast development was at Stage II (S2) without galactorrhea and no Axillary (A0) and Pubic Hair (P0). The thyroid gland was not palpable. On genital examination no abnormalities were detected. Ophthalmologic examination was normal (Table 1).

\begin{tabular}{|c|c|c|}
\hline \multirow{2}{*}{$\frac{\text { Value }}{\text { White Blood Count (WBC) }}$} & \multicolumn{2}{|r|}{ Range } \\
\hline & 6000 & $4-10 \times 103 / \mathrm{mm}^{3}$ \\
\hline Red Blood Cell Count (RBC) & 3.17 & $3.93-5.22 \times 106 / \mathrm{mm}^{3}$ \\
\hline Hemoglobin & 9.2 & $11-16 \mathrm{~g} / \mathrm{dl}$ \\
\hline Fasting glycemia & 66 & $70-104 \mathrm{mg} / \mathrm{dl}$ \\
\hline BUN & 27.3 & $17-43 \mathrm{mg} / \mathrm{dl}$ \\
\hline Carotenemia & 0.82 & $0.66-1.44 \mathrm{mg} / \mathrm{dl}$ \\
\hline Aspartate Aminotransferase (AST) & 35 & $0-35 U / L$ \\
\hline Alanine Aminotransferase (ALT) & 30 & $0-45 \mathrm{U} / \mathrm{L}$ \\
\hline Total bilirubin & 0.11 & $0.3-1.2 \mathrm{mg} / \mathrm{dl}$ \\
\hline Alkaline phosphatase & 143 & 30-120UI/L \\
\hline Cholesterol & 186 & $140-240 \mathrm{mg} / \mathrm{dl}$ \\
\hline Triglyceride & 117.1 & $50-150 \mathrm{mg} / \mathrm{dl}$ \\
\hline Total protein & 6.5 & $6.6-8.5 \mathrm{mg} / \mathrm{dl}$ \\
\hline TSH & 75 & $(0.5-4) \mu \mathrm{IU} / \mathrm{ml}$ \\
\hline Total thyroxin (TT4) & $<1$ & $60-120 \mathrm{nmol} / \mathrm{L}$ \\
\hline Total triiodothyronine (TT3) & $<0.4$ & $0.9-2.8 \mathrm{nmol} / \mathrm{L}$ \\
\hline Follicle stimulating hormone (FSH) & 5.1 & $3-8 \mathrm{IU} / 1$ \\
\hline Luteinizing Hormone (LH) & 0.2 & 1-7UI/L \\
\hline Estradiol (E2) & 125 & $25-100 \mathrm{pg} / \mathrm{ml}$ \\
\hline Prolactin (PRL) & 29.6 & $2.7-8.7 \mathrm{ng} / \mathrm{ml}$ adult female \\
\hline Morning cortisol 08;00 & 102 & $45-220 \mathrm{ng} / \mathrm{ml}$ \\
\hline
\end{tabular}

Auto antibodies and anti Tg against thyroid gland were negative. Thyroid ultrasound showed absence of thyroid gland in normal location. Scintigraphy with Technetium 99 showed light isotope uptake in the sublingual region and absence of isotope uptake in the normal thyroid position. Abdominal and pelvic ultrasound showed: Adult size uterus $66 \times 34 \times 24 \mathrm{~mm}$ and endometrial thickness $6 \mathrm{~mm}$. Right ovary was enlarged with a cyst measuring $83 \times 61 \mathrm{~mm}$, left ovary was enlarge measuring 38x26 mm. Liver, spleen, pancreas, both kidneys were within normal range. CT scan showed enlargement of both ovaries with a mass in the right one. Pituitary Magnetic Resonance Imaging (MRI) showed homogenous generalized enlargement of the pituitary gland.

These results were consistent with the diagnosis of primary hypothyroidism as a result of thyroid agenise. She was treated with L-Thyroxin $25 \mathrm{mcg} /$ day for the first two weeks than to $50 \mathrm{mcg}$ once daily fasting in the morning. Vaginal bleeding was stopped after few days. Breast development, size of uterus and ovaries returned to the prepubertal stage after six months of the L-thyroxin therapy.

\section{Discussion}

The cause of vaginal bleeding must be sought when bleeding occurs in young girl, like in this case, and clinical presentation may help in establishing of the correct diagnosis. In general, children with hypothyroidism present with delayed pubertal development and short stature, meanwhile children with precocious puberty present with pubertal growth spurt and advance bone age $[2-5,8]$. Hypothyroidism associated with paradoxical precocious puberty was first described by Kendle in 1905 [5,8]. Bone age was estimated at was 2 year and 9 months using the Greulich and Pyle method. Severe hypothyroidism is associated with hyperstimulation of the ovaries, resulting in metrorrhagia and precocious [9]. The exact mechanism of this paradoxical phenomenon is unclear; however, several theories have been put forward.

The bilaterally enlarged (Figure 1A-1C) and multicystic ovaries were suggestive of ovarian hyperstimulation rather than of autonomous endocrine ovarian activity as seen in secreting ovarian 
tumors. Very high levels of TSH seen in profound hypothyroidism interact with FSH receptor inducing FSH-like effects on gonads in the absence of LH effects, a phenomenon called "specificity spillover" because TSH and FSH, along with (LH) and Human Chorionic Gonadotropin (HCG), share a common beta subunit. It is theorized that in large amounts, TSH can activate the FSH receptor secondary to this common subunit. This stimulates ovaries resulting in polycystic ovaries, uterine bleeding and breast enlargement in girls without increase in androgens. This explains also the absence of axillary and pubic hair [2,4]. Also, in this case the child didn't have axillary or pubic hair.
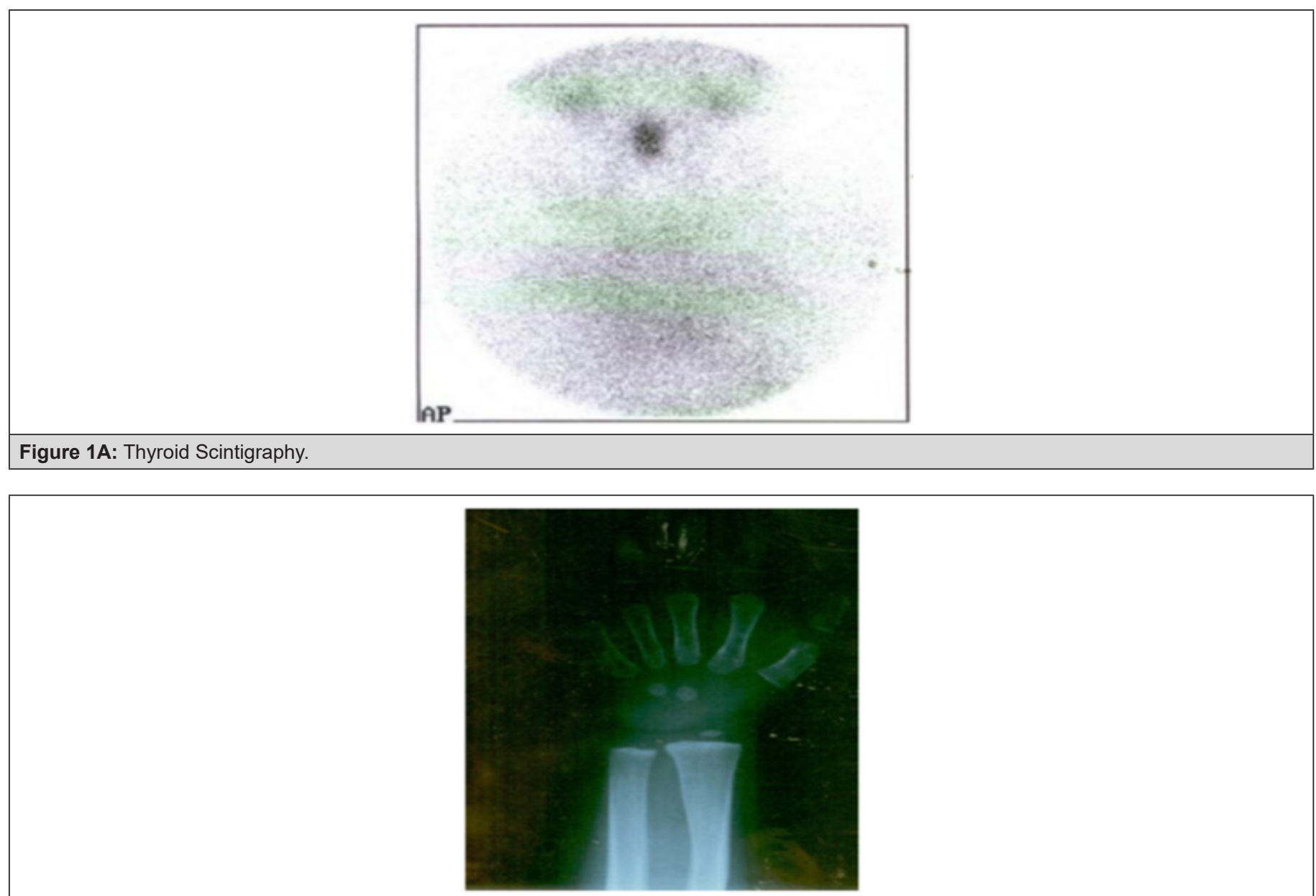

Figure 1B: Bone age.

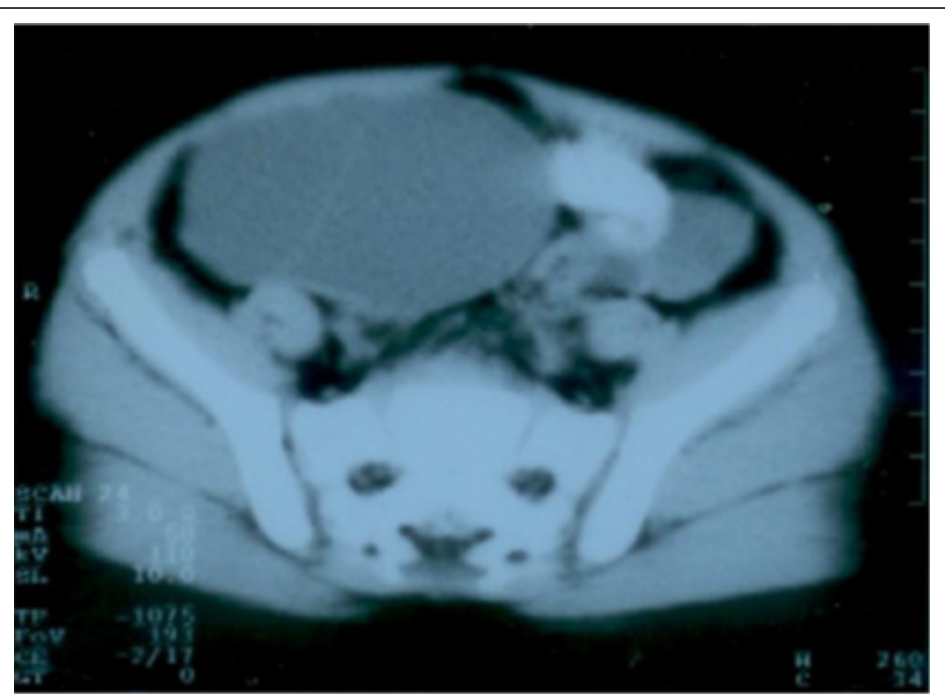

Figure 1C: Abdominal Ct scan. 
a. Other investigators have proposed that patients who have ovarian hyper stimulation syndrome due to hypothyroidism may have a mutation in the FSH receptor that may further increase the sensitivity of the receptor to TSH [5].

b. Prolactin theory: Hyperprolactinemia, which was present in our patient, has two etiologies. Some postulate that the thyrotrope hyperplasia in the pituitary compresses the pituitary stalk, thereby disrupting hypothalamic inhibition tonus of prolactin. When thyroid hormone is low, TRH increases lead to increased levels of prolactin because TRH is also known to stimulate prolactin. Hyperprolactinemia enhances the sensitivity of the ovaries to circulating gonadotropins and on the other hand reduces gonadotropin clearance and decreases dopaminergic and opioid tones at hypothalamic pituitary axis $[2,3,6]$. The PRL level was found increased in our case.

c. Overlap theory. Continuous high TRH level stimulates FSH secretion as well $[2,3]$.

Pituitary enlargement from undiagnosed hypothyroidism or the absence of the appropriate hormone treatment results in secondary hypertrophy or hyperplasia of the thyrotrophic cells in the anterior lobe of the pituitary gland $[1,7]$. Majority of these patients reported in literature have bilateral ovarian masses but, in our case, we have a unilateral ovarian mass and the opposite ovary was found to be larger than expected. Replacement thyroid hormone results cessation of vaginal bleeding, regression of breast development, disappear of the cyst [2-4,8-10]. It would be very reasonable to include a TSH in the laboratory evaluation of a child with an ovarian cyst causing vaginal bleeding or precocity, in order to avoid unnecessary surgery on the ovaries and to start immediately the treatment of hypothyroidism.

\section{Conclusion}

Children with precocious puberty having decreased growth velocity and bone age delay should be assessed for hypothyroidism.

\section{References}

1. Berberoğlu M (2009) Precocious Puberty and Normal Variant Puberty: Definition, etiology, diagnosis and current management. J Clin Res Pediatr Endocrinol 1(4): 164-174.

2. Osman HA, Al Jurayyan NAM, Babiker AMI, Al Otaibi HMN, AlKhalifah $\mathrm{RDH}$, et al. (2017) Precocious puberty: An experience from a major teaching hospital in Central Saudi Arabia. Sudan J Paediatr 17(1): 19-24.

3. Cherella CE, Wassner AJ (2017) Congenital hypothyroidism: insights into pathogenesis and treatment. Int J Pediatr Endocrinol 11: 1-8.

4. Rastogi MV, LaFranchi SH (2010) Congenital hypothyroidism. Orphanet J Rare Dis 5: 17 .

5. Rohani F, Salehpur S, Saffari F (2012) Etiology of precocious puberty, 10 years study in Endocrine Research Centre (Firouzgar), Tehran. Iran J Reprod Med 10(1): 1-6.

6. Ghaemi N, Vakili R, Bagheri S (2013) Precocious Puberty: An Unusual Presentation of Hypothyroidism. Int J Pediatr 1(2): 51-54.

7. Cabrera SM, DiMeglio LA, Eugster EA (2013) Incidence and Characteristics of Pseudoprecocious Puberty Because of Severe Primary Hypothyroidism. J Pediatr 162(3): 637-639.

8. Kasem SB (2016) Precocious Puberty with Primary Hypothyroidism due to Autoimmune Thyroiditis. (J Banagladesh Coll Phys Surg 34(1): 45-47.

9. Chemaitilly W, Thalassinos C, Emond S, Thibaud E (2003) Metrorrhagia and precocious puberty revealing primary hypothyroidism in a child with Down's syndrome. Arch Dis Child 88(4): 330-331.

10. Ozgen T, Güven A, Aydin M (2009) Precocious puberty in a girl with Down syndrome due to primary hypothyroidism. Turk J Pediatr 51(4): 381-383. 